\title{
Development of Learning Module on Oil and Beef Adulteration to Improve Students' Understanding in Analytical Chemistry Course
}

\author{
Yopita Diana ${ }^{1}$, Nina Gusti ${ }^{1}$, Rina Elvia ${ }^{1}$, Hartsa Arroka ${ }^{2}$ and M. Lutfi Firdaus ${ }^{1, *}$ \\ ${ }^{1}$ Graduate School of Science Education, University of Bengkulu \\ ${ }^{2}$ Department of Food Technology, Pasundan University \\ *Corresponding author. Email: lutfi@unib.ac.id
}

\begin{abstract}
The use of teaching material developed from laboratory research is one way that can be done to improve students' scientific literacy in accordance to the challenges of $21^{\text {st }}$ century learning. This research aimed to resolve the feasibility of the developed analytical chemistry module, to improve students' scientific literacy, and the student's response to the use of the module in the analytical chemistry course. The module was developed using the 4D type of Research and Development method, i.e., Define, Design, Develop, and Disseminate. The quality of module was determined by an expert validation test. The scientific literacy was measured by a pre-test and post-test with essay questions. Relied on the results of expert validation, the module results on the content eligibility aspect of $92 \%$, the presentation feasibility aspect of $85 \%$, the language assessment aspect of $88.3 \%$, the graphic assessment aspect of $83.3 \%$, and overall results of $87.5 \%$ with a very good category. The averages of pre-test and post-test scores were 28.67 and 82.74. Based on the results of the hypothesis test, it was concluded that there was an increase in students' scientific literacy by using a module in the analytical chemistry course. The students' response to the use of the module in learning activities was $82.00 \%$ with a very good category and the assessment of the module was $86.17 \%$ with a very good category.
\end{abstract}

Keywords: Module, $R$ and D, Scientific literacy, $4 D$ models.

\section{INTRODUCTION}

Analytical chemistry is a compulsory subject in the Chemical Education Study Program, University of Bengkulu. Analytical chemistry course has 2 credits subject and taught to fourth-semester students. As part of the chemistry discipline, analytical chemistry is considered difficult to understand conceptually. One of the concepts in the analytical chemistry syllabus is to elaborate on the concept about the principle of chemical compound analysis using molecular Ultraviolet-Visible Spectroscopy and how to apply them in everyday life. For this purpose, the UV-Vis Spectrophotometry analysis can be developed in teaching material. The learning module is one of the applied teaching materials. It is completely needed by students as a reference or a learning standard in the classroom or self-learning, therefore it overcomes the delayed understanding of students to comprehend the learning concept compared to the classmates. Some previous studies in the use of a module in learning show that the use of a module can improve scientific literacy skills [1]. This learning module is about the analysis of impurity elements in lubricating oils and beef due to the result of frequent counterfeiting. A good education and also wise attitude are strongly needed to determine the quality of human resources.

The $21^{\text {st }}$ century learning integrates literacy, knowledge, skills, attitudes, and technology expertise. Improving students' skills related to the concept of chemistry and its function has a close link to the improvement of scientific literacy. This approach involves social issues that require scientific concept components in decision making and to overcome in 
problem-solving [2]. One of learning scientific literacy can be conducted through laboratory research because it is an integral part of teaching and learning activity. A previous study shows that inquiry-based laboratory activity can improve scientific literacy [3]. According to the results of interviewing some chemical education students of analytical chemistry course, it states that the stimuli and indicators to improve scientific literacy have not been implemented. Scientific literacy is a compulsory skill for students. It must be improved so they can adapt to future technological developments.

The material that can be developed in a learning module to improve students' scientific literacy is the analysis of impurity elements or compounds in lubricating oils and beef by the UV-Vis spectrophotometry method. Lubricating oils are used in vehicle engines, where the efficiency and effectiveness of vehicle engine performance are strongly affected by the condition of lubricating oils used [4]. These lubricating oils can be renewed for a long period. Similar to lubricating oil, the high price of beef is the reason for the increasing prevalence of counterfeiting and mixes the beef with other cheaper materials. Relied on the description above, researchers are interested in developing an analytical chemistry module based on laboratory research to improve students' scientific literacy on UV-Vis Spectrophotometry and its uses on analysis of impurity elements in some samples. In this research, the UV-Vis Spectrophotometry analysis was implemented to analyse impurity elements in lubricating oils and beef.

\section{RESEARCH METHODS}

The study was conducted in the Analytical Chemistry course to the fourth-semester students of Chemistry Education, University of Bengkulu. The type of study was a 4D model of Research and Development ( $\mathrm{R}$ and $\mathrm{D})$ method that consist of Define, Design, Develop, and Disseminate. The module writing content was a process of preparing learning material. It was arranged systematically until accessible by students in the learning process. This research used modified Borg \& Gall's combined with Thiagarajan 4D research and development model $[5,6]$.

Define stage was an initial analysis. It was conducted to collect information and needs in the study process. Module needs analysis was conducted to identify and to determine the developed module. The initial analysis included syllabus analysis, student characteristics analysis through students' interviews and material analysis. This module needs analysis must emphasize on learning material. The learning material developed in this study was applied to the Analytical Chemistry course.
After conducting the analysis, it is needed to do research about science literacy to fourth-semester students in Chemical Education study program. This study was conducted by developing a learning module on UV-Vis spectrophotometry material. Laboratory experimental research on UV-Vis spectrophotometry and its uses in the analysis of impurity elements in lubricating oils and beef was conducted to support the learning material.

At the design stage, the learning module was drafted. The module design was adjusted with the competence and achieved scientific literacy indicator in analytical chemistry syllabus and based on the analysis result of impurity elements by UV-Vis spectrophotometry in the laboratory.

At the design stage, either it was designed some instruments of the study such as module validation instrument, item validation instrument, a rubric of scientific literacy skill, or student response instrument. At the develop stage, the expert validation trial was conducted on the module and test items. Module validation is assessed at a minimum by 3 professional judgments (expert judgment) of certified professionals [7]. The feasibility test result was used as a reference to do improvement of the teaching materials and test items. At this stage, it was also conducted a small-scale test for the analytical chemistry course to determine validity, reliability, level of difficulty, and discrimination power. At the disseminate stage, an analytical chemistry module was conducted to determine the effect of the module used on students' scientific literacy. The trial was conducted on the fourth-semester students of the Chemical Education study program, analytical chemistry course on UV-Vis Spectrophotometry and its use for the analysis of impurity elements. The test was one group pre-test - post-test. The effect of the use of the module on students' scientific literacy was showed from the results of the pre-test and post-test on the indicators of scientific literacy.

\section{RESULTS AND DISCUSSION}

\subsection{Define}

In the define stage, an initial analysis was conducted to collect the information and needs in the development research process. The analysis stage involved syllabus analysis, student characteristics analysis through students' interviews and material analysis. Based on the review result, it was showed that the analytical chemistry course required the development of teaching materials to meet the challenges of $21^{\text {st }}$ century learning, one of them was to integrate scientific literacy skills. The module material was obtained from laboratory experimental research on UV-Vis spectrophotometry and its use for the analysis of impurity elements. 
Module development was used to improve students' scientific literacy.

\subsection{Design}

The result of the product design and analytical chemistry module draft was developed by containing some components in the design stage. The components contained the initial part, module content, conclusion, evaluation question, bibliography, stimulus list of scientific literacy, and glossary. The module design was arranged following the indicator needs and achieved competencies.

The first part of the module consists of a cover (front page), preface, table of contents, list of tables, and list of images. The front page had an attractive design and presented a good viewpoint. The front page as an initial attraction could interest student to learn. The contents are described using instruction, competency standards, learning objectives, concept maps, concept mastery checklists, and material description. The material description was the definition and working principle of UV-Vis spectrophotometry, sample measurement requirements, types of UV-Vis spectrophotometry, parts and functions of UV-Vis spectrophotometry, standard operational procedures in using UV-Vis spectrophotometer, analysis of impurity elements in lubricating oils and beef that provided with stimuli to improve students' scientific literacy $[8,9]$. In the end, there was a conclusion from the description of learning activities and was completed with evaluation questions, bibliography, stimulus list of students' literacy, and glossary.

\subsection{Develop}

At the develop stage, the learning module and test items validation were tested. This validation aimed to determine the feasibility of the module and items based on the assessment of 3 lecturers as the appraisal expert. The results of the assessment by the validators can be seen in the Table 1.

Table 1. Module validation test results

\begin{tabular}{ccc}
\hline Assessment Components & Percentage & Category \\
\hline The content eligibility & $92 \%$ & Valid \\
\hline The presentation feasibility & $85 \%$ & Valid \\
\hline The language assessment & $88.3 \%$ & Valid \\
\hline The graphic assessment & $88.3 \%$ & Valid \\
\hline Total percentage & $87.5 \%$ & Valid \\
\hline
\end{tabular}

Based on Table 1, it was concluded that the developed analytical chemistry module based on all assessment components were categorized as valid or suitable as teaching material and could be tested in the analytical chemistry course. The module assessment results are stated as valid or feasible as we obtained a percentage of eligibility results more than 70\% [10].

The results of the item validation based on expert judgment can be seen in the Table 2. Based on Table 2, the results of the item validation consisting of 5 questions were as the category of feasible (valid) and could be tested on a small scale in analytical chemistry course. This trial was conducted aiming to obtain the validity of the items, reliability, level of difficulty, and discrimination power. The results of the small-scale trials are stated in Table 3 .

Table 2. Item Validation Results

\begin{tabular}{|c|c|c|c|c|c|}
\hline \multirow[t]{2}{*}{ Items } & \multicolumn{3}{|c|}{ Validator } & \multirow{2}{*}{$\begin{array}{l}\text { Assessment } \\
\text { Percentage }\end{array}$} & \multirow[t]{2}{*}{ Criteria } \\
\hline & V1 & $\mathrm{V2}$ & V3 & & \\
\hline 1 & 4 & 4 & 4 & $80 \%$ & Valid \\
\hline 2 & 4 & 4 & 5 & $86.7 \%$ & Valid \\
\hline 3 & 3 & 4 & 5 & $80 \%$ & Valid \\
\hline 4 & 5 & 4 & 4 & $86.7 \%$ & Valid \\
\hline 5 & 5 & 4 & 5 & $93.3 \%$ & Valid \\
\hline \multicolumn{4}{|c|}{ Total Percentage } & $85.3 \%$ & Valid \\
\hline
\end{tabular}

Table 3. The result of validity of the items, reliability, level of difficulty, and the discrimination power (DP)

\begin{tabular}{ccccc}
\hline Items & DP $(\%)$ & $\begin{array}{c}\text { Level of } \\
\text { Difficulty }\end{array}$ & Correlation & $\begin{array}{c}\text { Correlation } \\
\text { Sign }\end{array}$ \\
\hline 1 & 62.50 & Medium & 0.747 & Very Significant \\
2 & 87.50 & Medium & 0.690 & Significant \\
3 & 50.00 & Medium & 0.606 & Significant \\
4 & 60.00 & Medium & 0.626 & Significant \\
5 & 50.00 & Medium & 0.817 & Very Significant \\
\hline Mean & Standard & Correlation & Reliability & Total Subject \\
$=15.07$ & $\begin{array}{c}\text { Deviation } \\
=3.20\end{array}$ & $\begin{array}{c}\text { XY } \\
=0.68\end{array}$ & Test $=0.81$ & $=15$ \\
\hline
\end{tabular}

Based on the Table 3 at the validity test item, it was found that 2 items number 1 and 5 were stated as very significant, which indicated both questions had a high correlation to the total score. Item number 2, 3, and 4 were stated as significant. It showed that all three items had a fairly correlation to the total score. At the level of difficulty test of the five items, it showed as a medium category. At the power discrimination, it showed questions number 1, 3, 4, and 5 as good categories while item number 2 was a very good category. The reliability score was 0.81 and had a very high level of reliability. Based on all the test results obtained, it was concluded that all the questions were appropriate to be used by students to improve their scientific literacy.

\subsection{Disseminate}

Finally, at the stage of disseminate, the module was tested on the 30 students of the Chemical Education study program. The items tested were based on the seven indicators of students' scientific literacy, namely (1) identifying valid scientific opinions, (2) conducting 
effective literature searches, (3) understanding elements in research design, (4) making graphs from data, (5) solving problems using quantitative skill, including statistics, (6) understanding and interpreting statistics, (7) making inferences, predictions, and conclusions based on quantitative data. The result of the pre-test and post-test scores measurement in each item can be seen in the Figure 1.

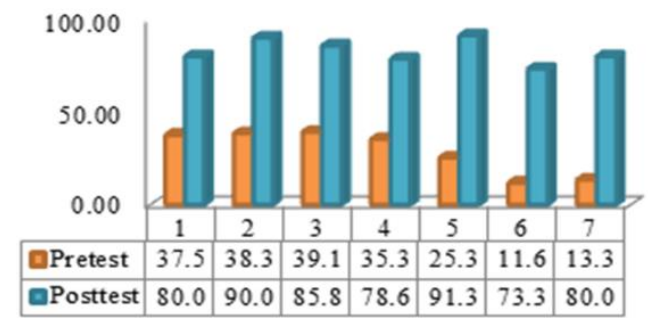

Figure 1. Scores of pre-test and post-test

Based on the results of the pre-test and post-test measurement in the Figure 1, it showed that the highest improvement was in indicator 5 with 91.33 as a post-test score, namely solving problems using quantitative skills, including basic statistics. It means the students were able to calculate the percentage of contaminants in the impurity elements of the sample in the item number 5. This indicated that the module provided could stimulate students to achieve scientific literacy skills and the competencies of an analytical chemistry course achieved on UV-Vis spectrophotometry topic.

The lowest indicator improvement of the post-test score was indicator 6 of 73.33. Indicator 6 was an indicator to understand and interpret basic statistics. From the score, it was stated that in this indicator some students had not been able to answer the question properly and correctly. It was because the stimulus provided to the module had not been comprehended and understood completely, even though the average score was as a fairly good category [11].

The post-test score of indicators 1, 2, 3, 4, and 7 were not significantly different from indicator 5 , as the result showed that the module provided have been adjusted and arranged in line with indicators of scientific literacy. The provided module was able to stimulate and improve students' scientific literacy. This was indicated by the average post-test score where there was an improvement in students' scientific literacy after treated with the UV-Vis spectrophotometry learning module [12].

The $\mathrm{N}$-gain score of each item could be seen in the Figure 2. Figure 2 shows that the biggest improvement in $\mathrm{N}$-gain on indicator 5 was 0.88 and the smallest $\mathrm{N}$ gain on indicator 4 was 0.67 . Entirely the average $\mathrm{N}$ gain score was 0.76 as a high category. It means that the seven indicators have an effect on a significant increase.

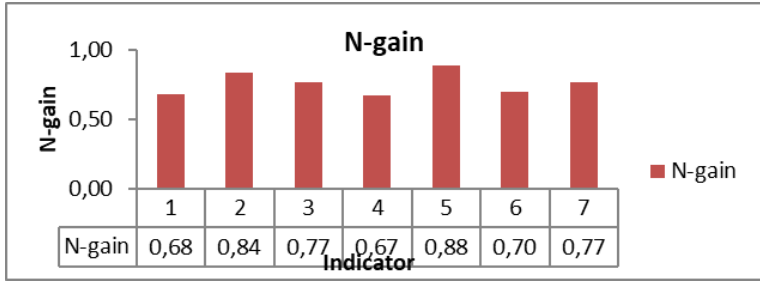

Figure 2. N-gain scores for each item

Student learning response questionnaire was conducted to determine student learning responses in use of analytical chemistry module. In the student interest questionnaire, the ideal maximum score for each item is 4 and the ideal minimum score for each item is 1. The results of the student response questionnaire are presented in table 4.

Table 4. Results of Students' Responses

\begin{tabular}{lcc}
\hline \multicolumn{1}{c}{ Students' Responses } & Percentage & Category \\
\hline $\begin{array}{l}\text { Learning process with } \\
\text { module }\end{array}$ & $82.00 \%$ & Very Good \\
\hline $\begin{array}{l}\text { Module used in learning } \\
\text { process }\end{array}$ & $86.17 \%$ & Very Good \\
\hline
\end{tabular}

Based on Table 4, the results of the students' questionnaire responses to the module have a range percentage of $81-100 \%$ with a very good category. This high percentage of students' responses showed that the module was accepted by the students as teaching material for an analytical chemistry course on the UVVis spectrophotometry topic, and its application for the analysis of impurity compounds in lubricating oils and beef.

\section{CONCLUSION}

In summary, the developed module gave an improvement on the content eligibility of $92 \%$, the presentation feasibility of $85 \%$, the language assessment of $88.3 \%$, the graphic assessment of $83.3 \%$, and the total score of $87.5 \%$ that lies in a very good category. The averages of pretest and posttest scores were 28.67 and 82.74. Based on the results of the hypothesis test, it was concluded that there was an increase in students' scientific literacy using a module in the analytical chemistry course. The student responses to the use of module in learning activities were $82.00 \%$ and the assessment of the module was $86.17 \%$, both of them lies within the very good category.

\section{REFERENCES}

[1] Wahyono, Suciati, Sutarno. Development of environmental pollution module based on problem posing accompanied by spider concept map to empower science process skills and ability to analyze students of sman 1 sumberlawang. Journal 
of Bioeducation, 2014, Vol. 7, 2, Pg . 32-38, ISSN: 1693-2654.

[2] Stefanova, Y., Minevska, M., \& Evtimova, S. Scientific literacy: problems of science education in bulgarian school. Journal of Problems of Education in the 21st Century. 2010, Volume 19, No. 1, pp. 113-118.

[3] Rakhmawan, Aditya. Design of science literacybased learning inquiry in laboratory activities. Journal of Natural Sciences Research and Learning. 2015, Volume 1, Issue 1, Pg. 143-152.

[4] Diatniti, Wayan., Supriyanto, Amir., Pauzi, Gurum Ahmad. Analysis of the declining quality of lubricating oil in motor vehicles based on viscosity, color, and number of impurity materials. Journal of Theory and Application. 2015, Volume.03, No.02.

[5] Winarni, Endang Widi. Theory and Practice of Qualitative Quantitative Research. Jakarta: Bumi Aksara, 2018.

[6] Arikunto, Suharsimi. Research Procedure A Practical Approach. Revised Edition 6. Jakarta: Rineka Cipta, 2009.

[7] Gall, M. D., Borg, W. R., \& Gall, J. P. Educational research: An introduction. Longman Publishing, 1996.
[8] Kuntzleman TS, Jacobson EC. Teaching Beer's law and absorption spectrophotometry with a smart phone: a substantially simplified protocol. Journal of Chemical Education. 2016 Jul 12;93(7):124952.

[9] Passos ML, Saraiva ML. Detection in UV-visible spectrophotometry: Detectors, detection systems, and detection strategies. Measurement. 2019 135, 896-904.

[10] Akbar, Sa'dun. Learning Instrument Instruments. Bandung: Remaja Rosdakarya Offset, 2013.

[11] Williams LB, Shelton BJ, Gomez ML, Al-Mrayat YD, Studts JL. Using Implementation Science to Disseminate a Lung Cancer Screening Education Intervention Through Community Health Workers. Journal of Community Health. 2020 Jun 27: 1-9.

[12] Steinert Y, Mann K, Centeno A, Dolmans D, Spencer J, Gelula M, Prideaux D. A systematic review of faculty development initiatives designed to improve teaching effectiveness in medical education: BEME Guide Medical teacher. 2006 , 28(6): 497-526. 